\title{
Modes of climate variability and their relationships with interhemispheric temperature asymmetry: a Granger causality analysis
}

\author{
Umberto Triacca ${ }^{1}$ (D) \\ Received: 27 March 2020 / Accepted: 11 November 2020 / Published online: 25 November 2020 \\ (c) The Author(s) 2020
}

\begin{abstract}
The aim of this paper is to investigate the relationships among Interhemispheric Temperature Asymmetry (ITA) and the principal modes of natural variability: the Atlantic Multidecadal Oscillation (AMO), the Southern Oscillation Index (SOI), and the Pacific Decadal Oscillation (PDO). In particular, Granger causality tests are used to capture the linkages among these variables. Our analysis provides strong evidence that AMO causes ITA, the causal role of PDO is weak, and SOI seems to have no causal influence.
\end{abstract}

\section{Introduction}

The Interhemispheric Temperature Asymmetry (ITA) index is defined as the difference between the hemispheric mean surface air temperatures Northern Hemisphere (NH) minus Southern Hemisphere (SH). Recently, ITA has been proposed as an emerging indicator of climate change (Friedman et al. 2013); thus, it is of extreme interest to investigate the causes of ITA changes. In particular, it is important to establish if this indicator depends or not on internal variability. ${ }^{1}$ In fact, if a significant effect of the internal variability over ITA was present, this variable may not be a good indicator of climate change. The natural internal variability may mask the climate change signal. This is similar to global temperature, in which anthropogenic aerosols are believed to have masked GHGs over the middle of the twentieth century (Friedman et al. 2013).

\footnotetext{
${ }^{1}$ By natural internal climate variability, we mean variability that occurs in the absence of natural or anthropogenic forcing; that is, variability that occurs solely due to the internal dynamics of the coupled atmosphere-ocean-biosphere-cryosphere system (see DelSole (2011, p.909-910).
}

Umberto Triacca

umberto.triacca@univaq.it

1 Department of Computer Engineering, Computer Science and Mathematics, University of L'Aquila, I-67010 Coppito, Italy
The aim of this paper is to investigate the relationships among ITA and the principal modes of natural variability: the Atlantic Multidecadal Oscillation (AMO), the Southern Oscillation Index (SOI), and the Pacific Decadal Oscillation (PDO). In particular, Granger causality tests are used to capture the linkages among these variables. We use these indices (AMO, SOI, and PDO) because they are an appropriate way to represent the natural interannual variability. However, as far as AMO is concerned, it is important to note a growing line of research suggesting that much (if not most) of its variability is forced. See for example Bellucci et al. (2017), Murphy et al. (2017), Bellomo et al. (2018), Haustein et al. (2019), and Mann et al. (2020).

The paper is organized as follows: Section 2 describes the methodology used. Section 3 presents the empirical results. Section 4 provides a summary of the key result and provides ideas for future work.

\section{Testing for Granger causality}

Granger causality analysis is one of the most common data-driven approach for identifying causal relationships in climate science. A review of the use of Granger causality for the attribution of global warming is provided in Attanasio et al. (2013). The notion of Granger causality was first introduced by Wiener (1956) and later reformulated and formalized by Granger (1969). Conceptually, the idea of Granger causality is quite simple. A variable $y$ causes another variable $x$, with respect to a given information set, 
$I(t)$ available at time $t$, which is assumed to contain $x_{t-j}$ $j=0,1, \ldots$ if at time $t, x_{t+1}$ can be better predicted by using present and past values of $y$ than by not doing so, all other information in $I(t)$ (including the present and past of $x$ ) being used in either case. Clearly, Granger causality concerns the predictability of a given stochastic process one period ahead. Namely, if a process $y$ contains information in the past terms that helps in the prediction of the process $x$ one period ahead, and this information is contained in no other process used in the predictor, then $y$ Granger causes $x$.

The Granger causality tests are conventionally conducted by estimating a vector autoregressive (VAR) model. Consider a $k$-dimensional discrete-time stochastic process, $\left\{\mathbf{y}_{t}=\left(y_{1 t}, y_{2 t}, \ldots, y_{k t}\right)^{\prime} ; t \in \mathbb{Z}\right\}$. We say that $\left\{\mathbf{y}_{t} ; t \in \mathbb{Z}\right\}$ follows a vector autoregressive model of order $p$ if it satisfies:

$\mathbf{y}_{t}=\mathbf{D}_{t}+\mathbf{A}_{1} y_{t-1}+\mathbf{A}_{2} y_{t-2}+\ldots+\mathbf{A}_{p} \mathbf{y}_{t-p}+\epsilon_{t}$ for $t \in \mathbb{Z}$

where

$\mathbf{A}_{i}=\left[\begin{array}{cccc}a_{11, i} & a_{12, i} & \ldots & a_{1 k, i} \\ a_{21, i} & a_{22, i} & \ldots & a_{2 k, i} \\ \vdots & \vdots & \ddots & \vdots \\ a_{k 1, i} & a_{k 2, i} & \ldots & a_{k k, i}\end{array}\right]$,

$i=1,2, \ldots, p$ are fixed $(k \times k)$ coefficient matrices, $\mathbf{D}_{t}$ is a $(k \times 1)$ vector of deterministic terms and $\mathbf{u}_{t}=$ $\left(u_{1 t}, u_{2 t}, \ldots, u_{k t}\right)^{\prime}$ is a $k$-dimensional vector white noise with $E\left(\mathbf{u}_{t} \mathbf{u}_{t}^{\prime}\right)=\boldsymbol{\Sigma}_{u}$ non-singular.

It is well known that in a VAR model Granger noncausality is characterized by a set of restrictions on the VAR coefficients. In particular, we have that the variable $y_{h}$ does not Granger cause $y_{j}$ if and only if $a_{j h, i}=0$, for $i=1, \ldots, p$. Thus, in this system, we can check causality of $y_{h}$ for $y_{j}$ by testing the null hypothesis:

$H_{0}: a_{j h, i}=0$ for $i=1, \ldots, p$.

We observe that the characterization of non-causality holds regardless of the integration order of the variables. ${ }^{2}$ However, when we test the null hypothesis (1) it is important to distinguish between $I(0)$ and $I(d)$ processes. If all considered variables are $I(0)$, we can use standard Waldor $F$-tests. In contrast, if one or more variables of the VAR are $I(d)$, the standard Wald- or $F$-tests for linear restrictions may not have the usual asymptotic distributions under the null. In this case, an appropriate procedure to test

\footnotetext{
${ }^{2}$ Consider a time series process $y_{t}$ defined by

$y_{t}=D T_{t}+z_{t}$,

where $D T_{t}$ is a deterministic trend (any function of time) and $z_{t}$ is an ARMA process. Then, $y_{t}$ is said to be trend-stationary or integrated of order $0(I(0))$ if $z_{t}$ is stationary and invertible. The process $y_{t}$ is said to be difference-stationary or integrated of order $d(\geq 1)(I(d))$ if $z_{t}$ have to be differenced $d$ time to achieve stationarity.
}

for non-causality is that suggested by Toda and Yamamoto (1995).

\section{The empirical results}

The data we consider are monthly observations of global temperatures and patterns of natural variability over the 1866-2016 sample period. The ITA index is calculated using data of global combined land and marine temperature anomalies (HadCRUT4) from the Met Office Hadley Centre, available at https://crudata.uea.ac.uk/cru/ data/temperature/ (Morice et al. 2012).

As far as data about the natural variability, we use the following indices:

- AMO: data available at www.esrl.noaa.gov/psd/data/ timeseries/AMO (Enfield et al. (2001));

- SOI: data available at www.cru.uea.ac.uk/cru/data/soi/ soi.dat (Ropelewski and Jones (1987));

- PDO: data available at https://www.ncdc.noaa.gov/ teleconnections/pdo (Zhang et al. 1997).

The AMO, also known as Atlantic Multidecadal Variability (AMV), is a climate cycle that affects the sea surface temperature (SST) of the North Atlantic Ocean (north of the equator). The AMO index is derived from the North Atlantic SST once any linear trend has been removed. This detrending is intended to remove the external forced signal. However, the application of linear detrending is probably not the appropriate method to eliminate this external forced signal (see Trenberth and Shea (2006), Ting et al. (2009), Mann et al. (2014), and Wills et al. (2019)).

The SOI is one measure of the large-scale fluctuations in air pressure occurring between the western and eastern tropical Pacific. More specifically, the SOI is calculated as the difference in air pressure anomaly between Tahiti and Darwin, Australia.

The PDO is the dominant mode of SST variability in the North Pacific. The PDO Index is defined as the first principal component of the monthly North Atlantic SST anomalies.

The time series of ITA, AMO, SOI, and PDO are shown in Fig. 1. A visual inspection of the plots suggests that all series could probably be considered realizations of processes $I(0)$ or at most $I(1)$. This suggestion is confirmed by the results of the unit root tests shown in Tables 1 and $2 .^{3}$ The only ambiguous case is that of ITA, where the Augmented Dickey-Fuller GLS test indicates the possible existence of a unit root. Thus, we will conduct our Granger causality analysis under two alternative assumptions:

\footnotetext{
${ }^{3}$ To carry out the unit root tests, we estimate the following regression for each variable of interest $y: y_{t}=a+b t+c y_{t-1}+c_{1} \Delta y_{t-1}+\ldots+$ $c_{k} \Delta y_{t-k}+u_{t}$. The number of lags $k$ has been chosen testing down from 24 lags the modified AIC criterion.
} 

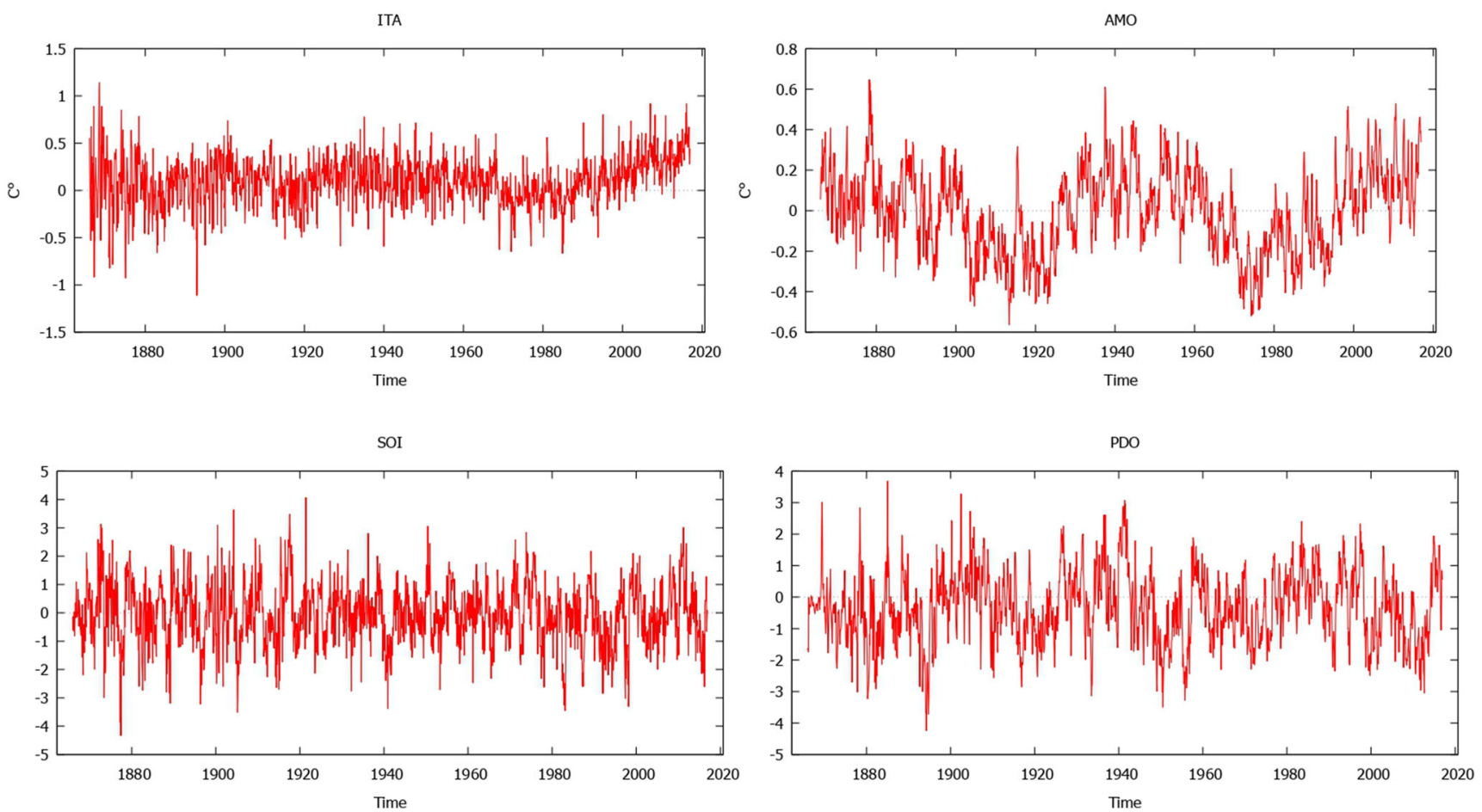

Fig. 1 Monthly time series over the period 1866-2016. Interhemispheric Temperature Asymmetry (ITA) index, Atlantic Multidecadal Oscillation (AMO), Southern Oscillation Index (SOI), and Pacific Decadal Oscillation (PDO)

- Assumption 1. All variables are $I(0)$;

- Assumption 2. AMO, SOI, PDO are I(0) and ITA is $I(1)$.

Assuming that ITA, AMO, SOI, and PDO variables are $\mathrm{I}(0)$, the null hypothesis $H_{0}$ can be tested by a standard F-test. In particular, we consider the following regression estimated by ordinary least squares:

$$
\begin{aligned}
I T A_{t}= & \alpha+\beta t+\sum_{i=1}^{p} \alpha_{i} I T A_{t-i}+\sum_{i=1}^{p} \beta_{i} A M O_{t-i} \\
& +\sum_{i=1}^{p} \gamma_{i} S O I_{t-i}+\sum_{i=1}^{p} \delta_{i} P D O_{t-i}+u_{t}
\end{aligned}
$$

Table 1 Augmented Dickey-Fuller test

\begin{tabular}{lcc}
\hline Variable & Test statistic & $p$ value \\
\hline ITA & -3.6282 & 0.0052 \\
AMO & -3.8451 & 0.0024 \\
SOI & -10.5353 & 0.0000 \\
PDO & -10.0755 & 0.0000 \\
\hline
\end{tabular}

The order selection criterion HQ was applied in order to determine the VAR order $p$. Allowing for a maximum order of 12 , the HQ criterion has selected $p=2$. The results for Granger non-causality tests are given in Table 3 . We find that AMO causes ITA whereas we cannot detect any effect of SOI on ITA, and the effect of PDO is weak.

It is important to note that the analysis of the ITA time plot may suggest the existence of a structural break in the late 1960s. Estrada et al. (2017), by applying the PerronYabu (PY) test to ITA, formally document the existence of a break in both the level and the slope of the trend

Table 2 Augmented Dickey-Fuller GLS test

\begin{tabular}{lll}
\hline Variable & Test statistic & $p$ value \\
\hline ITA & -1.4597 & 0.1351 \\
AMO & -3.4554 & 0.0005 \\
SOI & -9.0042 & 0.0000 \\
PDO & -4.2374 & 0.0001 \\
\hline
\end{tabular}


Table 3 Granger non-causality tests. Full sample: 1866:01-2016:12

\begin{tabular}{lll}
\hline & Test statistic & $p$ value \\
\hline All lags of AMO & $F(2,1800)=25.2496$ & 0.0000 \\
All lags of SOI & $F(2,1800)=0.813959$ & 0.4433 \\
All lags of PDO & $F(2,1800)=2.27275$ & 0.1033 \\
\hline
\end{tabular}

function occurring in $1968 .{ }^{4}$ Thus, ITA could be brokentrend stationary. Adopting this assumption, the Granger non-causality tests have been performed also within subsamples where no structural instabilities have been detected: 1866:01-1967:12 and 1968:01-2016:12. The HQ criterion has selected $p=2$ also in these sample periods. In Tables 4 and 5, the results of Granger non-causality tests, according to the abovementioned strategy, are reported. The causality from AMO to ITA can be accepted with great confidence in all periods whereas the evidence for causality from PDO to ITA is significant only in the first sub-period. ${ }^{5}$ There is no detectable causality from SOI to ITA.

Finally, we conduct the causality analysis assuming that the maximum integration order of the considered variables is 1 . Following the procedure of Toda and Yamamoto, we use the regression:

$$
\begin{aligned}
I T A_{t}= & \alpha+\beta t+\sum_{i=1}^{p+1} \alpha_{i} I T A_{t-i}+\sum_{i=1}^{p+1} \beta_{i} A M O_{t-i} \\
& +\sum_{i=1}^{p+1} \gamma_{i} S O I_{t-i}+\sum_{i=1}^{p+1} \delta_{i} P D O_{t-i}+u_{t}
\end{aligned}
$$

The results, reported in Table 6, are very similar to those obtained under the assumption that the considered time series are trend stationary. Also, in this case, the variable that presents the main causal role is AMO. ${ }^{6}$

This result agrees with the findings of Green et al. (2017), who found that the AMO index explains over $70 \%$ of the interhemispheric tropospheric temperature contrast.

\footnotetext{
${ }^{4}$ See the recent study (Friedman et al. 2020) for further discussion of the late 1960s interhemispheric SST shift.

${ }^{5}$ This finding could be explained by the fact that ITA time series is characterized by a stronger trend in the second sub-period. Probably, the presence of this trend masks the influence of the PDO on the ITA passing through the cyclical component of ITA time series.

${ }^{6}$ Following the suggestion of a referee, we have also considered the model without the linear trend $(\beta=0)$ in order to evaluate the robustness of Granger causality analysis. The results, available on request, are the same.
}

Table 4 Granger non-causality tests. Sub-sample: 1866:01-1967:12

\begin{tabular}{lll}
\hline & Test statistic & $p$ value \\
\hline All lags of AMO & $F(2,1212)=6.9495$ & 0.0010 \\
All lags of SOI & $F(2,1212)=0.187414$ & 0.8291 \\
All lags of PDO & $F(2,1212)=4.63144$ & 0.0099 \\
\hline
\end{tabular}

\section{Summary and future work}

In this paper, we have investigated the causal relationships among ITA and some patterns of natural variability (AMO, SOI, and PDO). Our analysis provides strong evidence that AMO causes ITA, the causal role of PDO is weak, and SOI seems to have no causal influence. Given the large effect of AMO over ITA, this variable may not be considered a good indicator of climate change. For the interhemispheric temperature asymmetry, natural variability partially masks the underlying anthropogenic global warming signal. This conclusion seems to be consistent with the evidence that Estrada et al. (2017) have recently provided using a different statistical methodology.

However, since AMO should be primarily controlled by external forcing, we want to study the relationship between AMO and ITA removing the forced signal in future research. In fact, if a forced component is present, the AMO index could no longer be considered a genuine measure of the natural variability. The causal link found in our analysis could be induced by this component. A different method of removing the forced component of the AMO signal should affect our results. In particular, using an improved measure of the natural variability, the causation from AMO to ITA could disappear.

Another point that we intend to investigate in future research concerns the Granger causality analysis in the frequency domain. The advantage of frequency-domain Granger causality lies in the disentanglement of the causality structure across a range of frequencies. This may yield new and complementary insights compared to the traditional version of Granger causality analysis conduced in this paper.

Table 5 Granger non-causality tests. Sub-sample: 1968:01-2016:12

\begin{tabular}{llc}
\hline & Test statistic & $p$ value \\
\hline All lags of AMO & $\mathrm{F}(2,578)=972.89$ & 0.0000 \\
All lags of SOI & $\mathrm{F}(2,578)=2.3847$ & 0.0930 \\
All lags of PDO & $\mathrm{F}(2,578)=0.33229$ & 0.7174 \\
\hline
\end{tabular}


Table 6 Toda-Yamamoto Granger non-causality tests. Full sample: 1866:01-2016:12

\begin{tabular}{lll}
\hline & Test statistic & $p$ value \\
\hline First two lags of AMO & $\mathrm{F}(2,1795)=10.0114$ & 0.0000 \\
First two lags of SOI & $\mathrm{F}(2,1795)=0.620903$ & 0.5357 \\
First two lags of PDO & $\mathrm{F}(2,1795)=2.4093$ & 0.0902 \\
\hline
\end{tabular}

Acknowledgments The author is grateful to the two anonymous referees for their helpful comments and suggestions that helped improve the quality of this paper.

Funding Open access funding provided by Università degli Studi dell'Aquila within the CRUI-CARE Agreement.

\section{Compliance with ethical standards}

Conflict of interest The author declares that he has no conflict of interest.

Open Access This article is licensed under a Creative Commons Attribution 4.0 International License, which permits use, sharing, adaptation, distribution and reproduction in any medium or format, as long as you give appropriate credit to the original author(s) and the source, provide a link to the Creative Commons licence, and indicate if changes were made. The images or other third party material in this article are included in the article's Creative Commons licence, unless indicated otherwise in a credit line to the material. If material is not included in the article's Creative Commons licence and your intended use is not permitted by statutory regulation or exceeds the permitted use, you will need to obtain permission directly from the copyright holder. To view a copy of this licence, visit http:// creativecommonshorg/licenses/by/4.0/.

\section{References}

Attanasio A, Pasini A, Triacca U (2013) Granger causality analyses for climatic attribution. Atmos Clim Sci 3:515-522

Bellomo K, Murphy LN, Cane MA, Clement AC, Polvani LM (2018) Historical forcings as main drivers of the Atlantic Multidecadal Variability in the CESM Large Ensemble. Climate Dynam 50:3687-98

Bellucci A, Mariotti A, Gualdi S (2017) The role of forcings in the twentieth-century North Atlantic multidecadal variability: the 1940-75 North Atlantic cooling case study. J Climate 30:7317-37

DelSole T, Tippett MK, Shukla J (2011) A significant component of unforced multidecadal variability in the recent accelerationof global warming. J Clim 24:909-926

Enfield DB, Mestas-Nunez AM, Trimble PJ (2001) The Atlantic Multidecadal Oscillation and its relationship to rainfall and river flows in the continental U.S. Geophys Res Lett 28:2077-2080
Estrada F, Martins LF, Perron P (2017) Characterizing and attributing the warming trend in sea and land surface temperatures. Atmsfera 30:163-187

Friedman AR, Hwang Y-T, Chiang JCH, Frierson DMW (2013) Interhemispheric temperature asymmetry over the twentieth century and in future projections. J Clim 26:5419-5433

Friedman AR, Hegerl GC, Schurer AP, Lee S-Y, Kong W, Cheng W, Chiang JCH (2020) Forced and unforced decadal behavior of the interhemispheric SST contrast during the instrumental period (1881-2012): contextualizing the late 1960s-early 1970s shift. J Climate 33:3487-3509

Granger CWJ (1969) Investigating causal relations by econometric models and cross spectral methods. Econometrica 37:424-438

Green B, Marshall J, Donohoe A (2017) Twentieth century correlations between extratropical SST variability and ITCZ shifts: AMO, PDO, and ITCZ variability. Geophys Res Lett 44:9039-9047

Haustein K, Otto FEL, Venema V, Jacobs P, Cowtan K, Hausfather Z, Way RG, White B, Subramanian A, Schurer AP (2019) A limited role for unforced internal variability in 20th century warming. $\mathrm{J}$ Climate 32:4893-4917

Mann ME, Steinman BA, Miller SK (2014) On forced temperature changes, internal variability, and the AMO. Geophys Res Lett 41:3211-3219

Mann ME, Steinman BA, Miller SK (2020) Absence of internal multidecadal and interdecadal oscillations in climate model simulations. Nat Commun 11:49

Morice CP, Kennedy JJ, Rayner NA, Jones PD (2012) Quantifying uncertainties in global and regional temperature change using an ensemble of observational estimates: The HadCRUT4 dataset. J Geophys Res 117:D08101

Murphy LN, Bellomo K, Cane M, Clement A (2017) The role of historical forcings in simulating the observed atlantic multidecadal oscillation. Geophysical Research Letters, 2016GL071337

Ropelewski CF, Jones PD (1987) An extension of the Tahiti-Darwin Southern oscillation index. Mon Weather Rev 115:2161-2165

Ting MF, Kushnir Y, Seager R, Li CH (2009) Forced and internal twentieth-century SST trends in the North Atlantic. J Climate 22:1469-1481

Toda HY, Yamamoto $T$ (1995) Statistical inference in vector autoregressions with possibly integrated processes. J Econ 66:225-250

Trenberth KE, Shea DJ (2006) Atlantic hurricanes and natural variability in 2005. Geophys Res Lett 33:L12704

Wiener N (1956) Modern mathematics for the engineer, chapter The theory of prediction. MacGrawHill, pp 165-190

Wills RC, Armour KC, Battisti DS, Hartmann DL (2019) Oceanatmosphere dynamical coupling fundamental to the Atlantic multidecadal oscillation. J Climate 32:251-272

Zhang Y, Wallace JM, Battisti DS (1997) ENSO-like interdecadal variability: 1900-93. J Climate 10:1004-1020

Publisher's note Springer Nature remains neutral with regard to jurisdictional claims in published maps and institutional affiliations. 